\title{
Influence of Welding Defects on Residual Stresses: Numerical study
}

\author{
I. FRIH ${ }^{\mathrm{a}^{*}}$, P.A. ADRAGNA ${ }^{\mathrm{b}}$, G. MONTAY \\ LASMIS, UMR ICD 6281, Université de Technologie de Troyes, 12 rue Marie Curie, 10004 \\ TROYES Cedex France
}

aintissar.frih@utt.fr, bpierre_antoine.adragna@utt.fr, 'cguillaume.montay@utt.fr

Keywords: Welding; Residual stresses; Defect; Numerical simulations.

\begin{abstract}
This paper presents a study on the application of the finite element methods to predict the influence of a defect on the residual stress distribution in a T-welded structure. A defect is introduced in a numerical model firstly without residual stress to see its impact (size and position) on the stress distribution. Secondly the most critical defect (determined previously) is simulated with a residual stress gradient. The obtained results are useful for computation stress concentration factor due to weld residual stresses.
\end{abstract}

\section{Introduction}

The T-welded constructions are widely used in various domains (transport, civil engineering, offshore ...). The risk of failure by fracture of such assemblies can be linked to several causes (weather conditions) or cyclic loading (fatigue). High strength low-alloy steels are among the nuances used for these applications due to their good weldability, high yield strength, and toughness [1].

Stresses in a welded structure are a combination of applied stress due to external load and residual stress due to welding processes $\left(\sigma=\sigma_{\text {applied }}+\sigma_{\text {residual }}\right)$. The presence of a high tensile weld residual stress may have significant effects on the final performance and can accelerate or delay many failure processes by causing fatigue and fracture [2]. Also, the failure of these structures is mainly due to pre-existing defect generally located in the toe of the weld [3,4]. Types of defect include porosity, inclusions, cracks, surface pores, etc.

Several studies have treated the harmfulness of crack defect on the behavior of welded structure $[4,6]$. However, understanding the effect of porosity defect during the presence of residual stress within the weld is still insufficient.

Welding residual stresses have important contribution on the performance of the structure. Taking them into account helps to improve the design and the selection of manufacturing process and materials $[7,8]$ but also to improve computation code for a better prediction of results (which is the purpose of this study).

For this, in the context of safe design, the stress concentration factor will be calculated for a particular defect size and a particular load applied.

\section{Finite elements method}

In this part of the paper, the FEM is used to determine the stress distribution into the weld considering 4 configurations:

- T-welded structure without defect and before introducing residual stresses.

- T-welded structure without defect and after introducing residual stresses.

- T-welded structure with defect and before introducing residual stresses.

- T-welded structure with defect and after introducing residual stresses.

Geometric model and meshing.

The implicit finite element calculation was performed using ABAQUS standard. All calculations are elastic and linear. The geometrical model of the T-welded structure is shown in Fig.1 with $w=10 \mathrm{~mm}, l_{1}=100 \mathrm{~mm}$ and $l_{2}=210 \mathrm{~mm}$. The distance between the plate -1 and the plate -2 is $0.1 \mathrm{~mm}$. 
The thickness of the structure is $40 \mathrm{~mm}$. The material is a HSLA S500MC steel with a Poisson's ratio $v$ of 0.3 , a Young's modulus $\mathrm{E}$ of $210 \mathrm{GPa}$ and yield strength $\sigma_{\mathrm{y}}$ of $520 \mathrm{MPa}$. For the T-welded structure, a plane strain condition was chosen to represent the $2 \mathrm{D}$ modeling. The finite element models was created using 6-node quadratic triangular element CPE6. 2550 elements were used to mesh partition- 1 and partition- 2 with an element size of approximately $0.2 \mathrm{~mm}$. The rest of the structure was coarsely meshed as shown in Fig. 2.

\section{Hypothesis.}

In the case of engineering consulting firm, to obtain a safe design of this structure, the reliability approach adopted is based on the method of "Stress-Resistance". The safe design is observed when $\mathrm{G}$ is strictly positive. The performance function $\mathrm{G}$ is given by [9]:

$$
G=\frac{\sigma_{\mathrm{y}}}{\mathrm{k}_{\mathrm{s}}}-\sigma_{11}
$$

where $\sigma_{11}$ is the stress according the $\mathrm{X}_{2}$ direction. The applied load $\mathrm{P}$ is chosen so that the safety factor of the yield strength $\mathrm{k}_{\mathrm{s}}$ is equal to 1,5. In this study, all configurations are under pressure of $44 \mathrm{MPa}$. A pressure is applied on the top of structure according the $\mathrm{Y}_{1}$ direction.

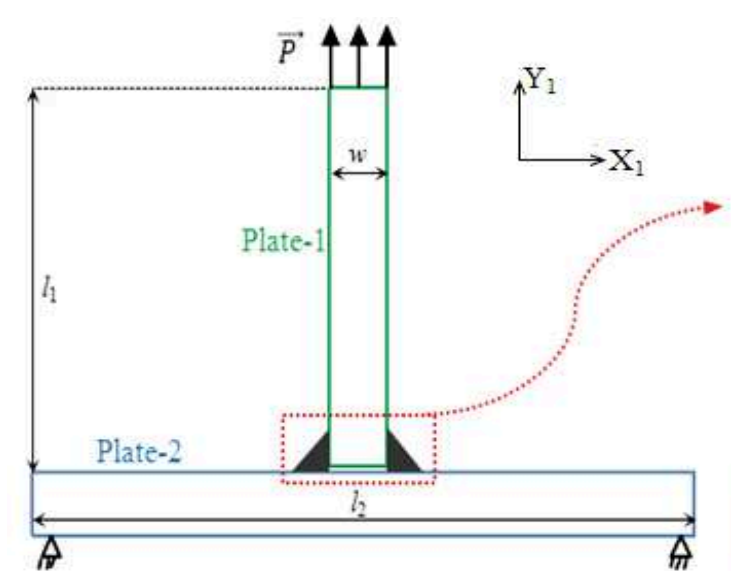

Fig. 1 The geometrical model of T-weld

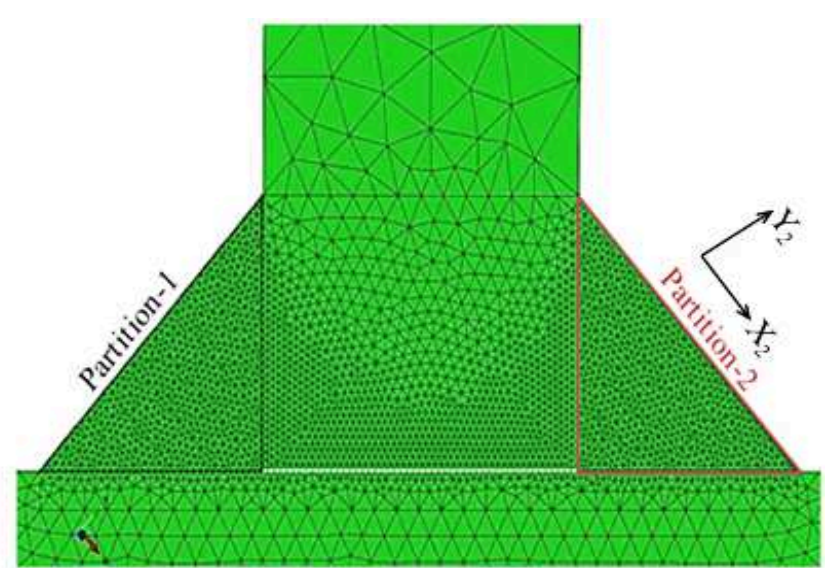

Fig. 2 FE mesh of the model

\section{Introdution residual stresses into FE models.}

It is necessary to introduce realistic stress conditions in the FEM to have a better prediction. We need a field that represents the residual stresses caused by a TIG weld and measured using the contour method. Due to the lack of data for the S500MC steel, the residual stress distribution shown in Fig.4 has been chosen approximately for this preliminary study. The stress gradient was simplified such that the residual stress distribution was introduced to the numerical model with discrete values over every $1 \mathrm{~mm}$ distance as shown in the example (Fig. 3). Thanks to ABAQUS, these initial stresses can be equilibrated in the first analysis step [10,11].

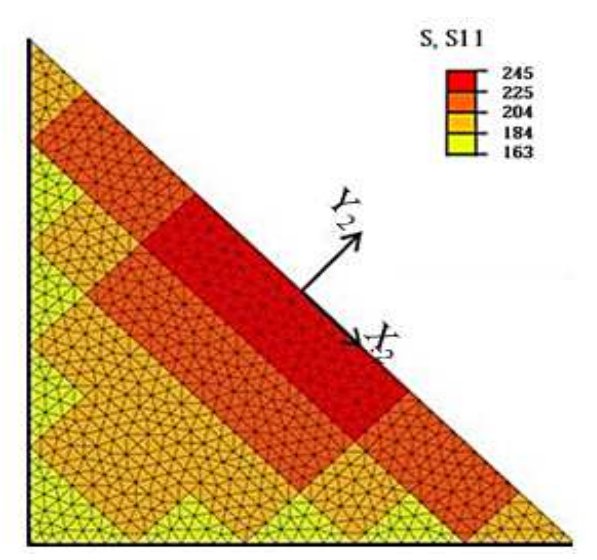

Fig. 3 Weld residual stress distributions

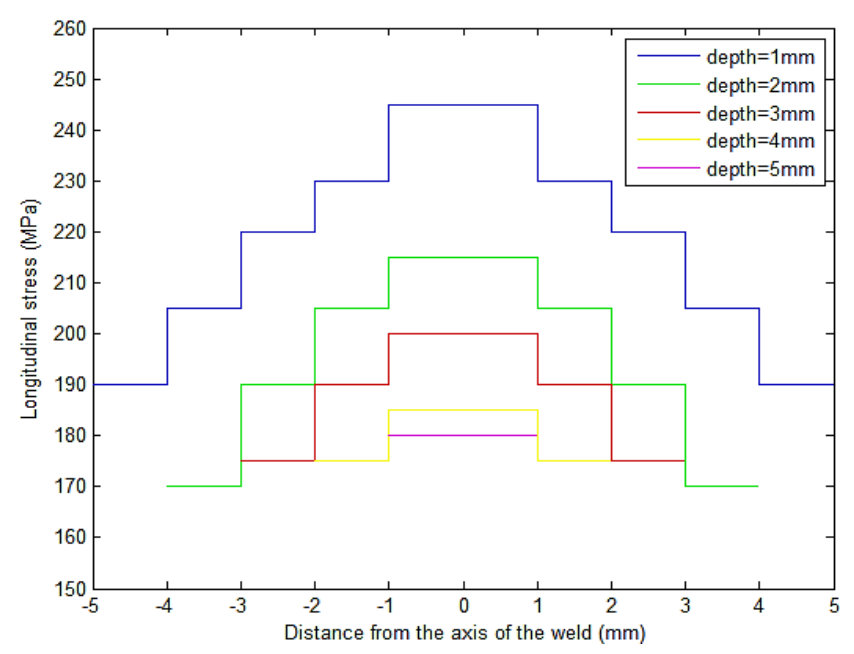

Fig. 4 Input residual stress 


\section{Finite elements analysis}

\section{Influence of residual stresses.}

In order to determine the influence of the residual stresses on the reliability of a T-welded structure, two configurations are simulated before and after introducing residual stress in the FEM as shown in Fig. 5-a and Fig. 5-b respectively. We compare $\sigma_{11}$ which is the stress according the $X_{2}$ direction. Fig. 5-a shows that the maximum stresses of $\sigma_{11}$, for the structure without residual stresses, is equal to $225.9 \mathrm{MPa}$ and it is located on the weld root zone.

According to FE results given after introducing residual stress in the weld as outlined by Fig. 3, the maximum stresses is equal to $345.4 \mathrm{MPa}$ and it is located on the weld toes zones (Fig. 5-b).

We can see the important role of the residual stress on the behaviour of the T-welded structure. There is a change in the intensity and in the localisation of the stress concentration.

Results given by numerical simulation shows that tensile residual stress shifts the dangerous zone from the weld root zone to the weld toes zones and increases the stress intensity.

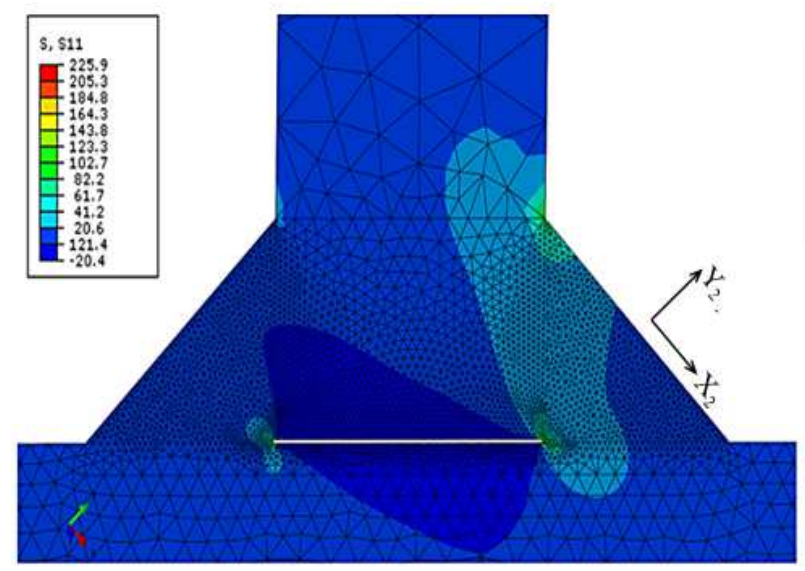

(a)

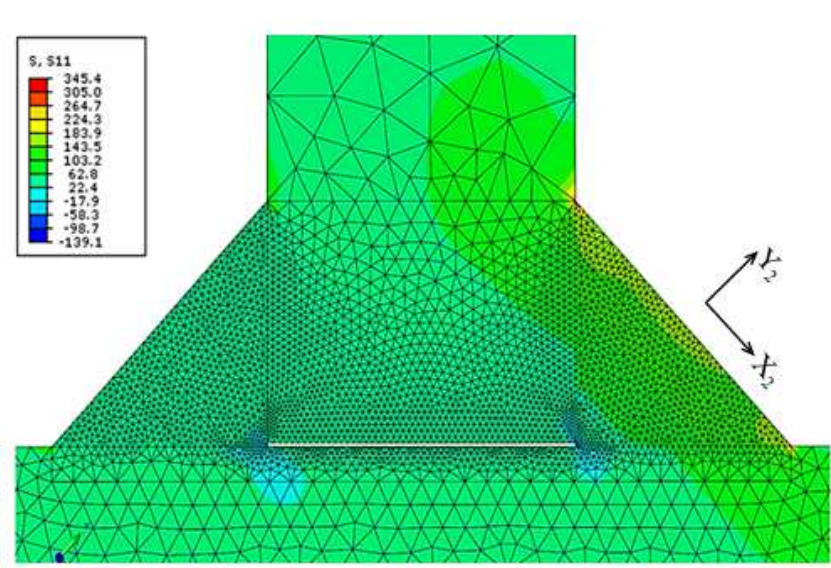

(b)

Fig. 5 The stress contour: (a) before introducing residual stress, (b) after introducing residual stress

Analysis of a defect in the weld.

A defect was introduced in the numerical model to see the impact of its parameters (Fig. 6) on the stress distribution. The exploration of the whole area of the weld, as shown in Fig. 7, helped to identify the most critical configurations of pre-existing defect in the structure.

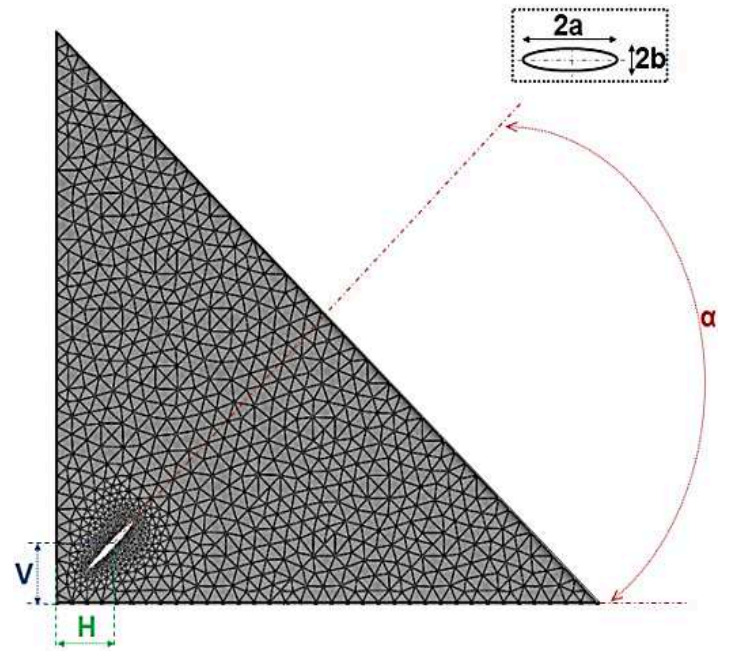

Fig. 6 The defect parameters in the weld

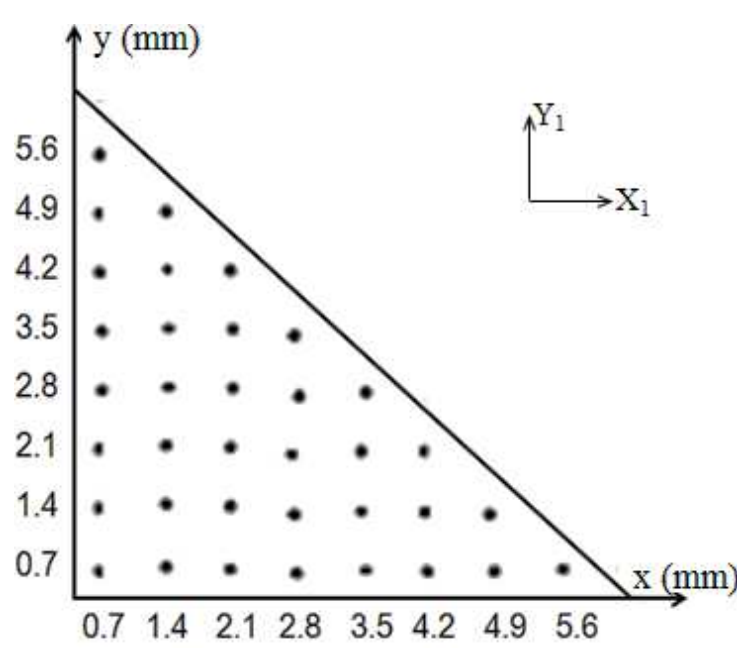

Fig. 7 Different positions of defect centre in the weld

A numerical study is performed in order to evaluate a stress concentration factor $\mathrm{k}_{\mathrm{t}}$ due to the presence of porosity. For each position and size of the defect, the stress concentration factor $\mathrm{k}_{\mathrm{t}}$ will be calculated by the following expression 


$$
k_{t}=\frac{\sigma_{\max }}{\sigma_{\text {nom }}}
$$

where $\sigma_{\text {nom }}$ is the nominal stress of the structure without a defect and $\sigma_{\max }$ is the maximal stress $\sigma_{11}$ of the structure containing a defect. The study was realised for two defect sizes $(2 \mathrm{a}=0.3 \mathrm{~mm}$ and $2 \mathrm{a}=1 \mathrm{~mm}$ ) and under these conditions: $\mathrm{a} / \mathrm{b}=0.1$ and $\alpha=45^{\circ}$.

\section{Results and discussions}

In this part of the paper, a defect is introduced in the FE model without residual stresses and secondly with residual stresses as initial conditions.

\section{Non-pre-stressed structure.}

The defect is introduced in the numerical model firstly without residual stresses. The defect center position was varied in the weld as shown in Fig. 7. For each position, the stress concentration factor was numerically calculated. Fig. 8 shows the cartography of the $\mathrm{k}_{\mathrm{t}}$ distribution in the weld for two defect sizes.

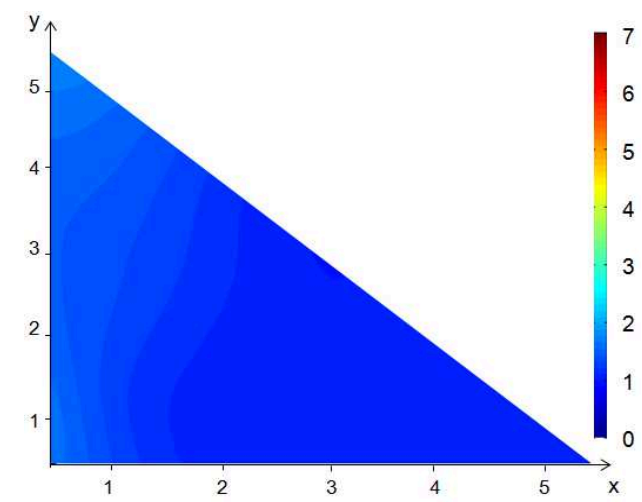

(a)

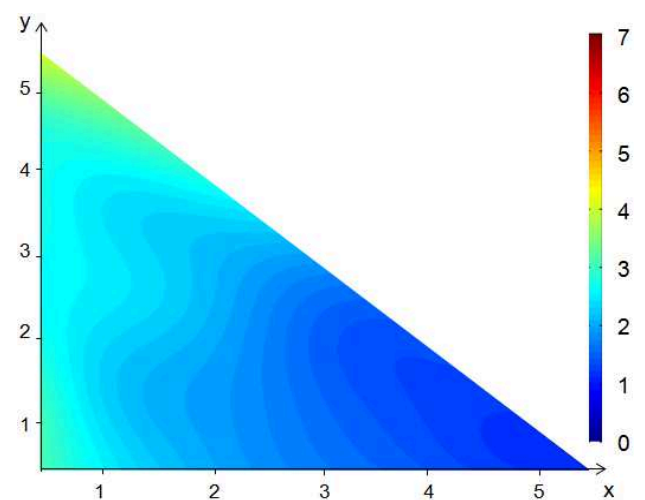

(b)

Fig. 8 Contours of the stress concentration factor $\mathrm{k}_{\mathrm{t}}$ : (a) $2 \mathrm{a}=0.3 \mathrm{~mm}$ (b) $2 \mathrm{a}=1 \mathrm{~mm}$

Defect size of $0.3 \mathrm{~mm}$ has low influence on the performance of the structure $\left(k_{t}^{\max }=1.7\right)$. However, for the defect size of $1 \mathrm{~mm}\left(k_{t}^{\max }=4.5\right)$, we can identify three zones in the weld:

- For $\mathrm{k}_{\mathrm{t}}<2$ : Security domain. Defect has low impact on the final behavior of the structure.

- For $\mathrm{k}_{\mathrm{t}}=2$ : Limit state. A reliability study will be interesting.

- For $\mathrm{k}_{\mathrm{t}}>2$ : Failure domain. The presence of a defect is not acceptable.

\section{Pre-stressed structure.}

Introducing residual stresses as initial conditions into the weld shows that the two sizes of the defect have a greater impact on the behaviour of the structure. For defect sizes of $0.3 \mathrm{~mm}$ and $1 \mathrm{~mm}, k_{t}^{\max }$ is equal to 4.2 and 7 respectively.

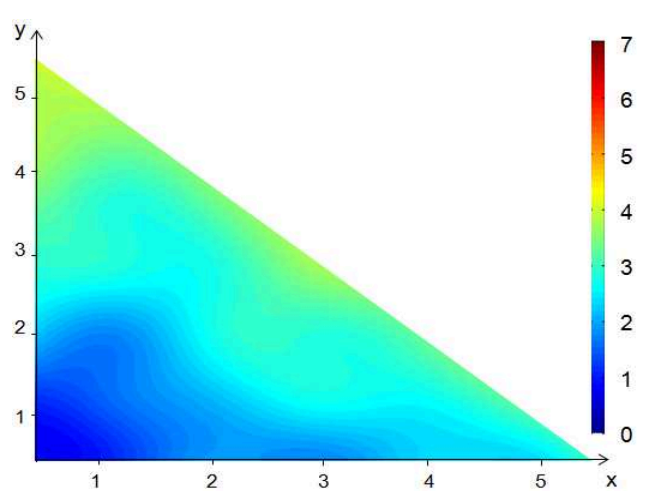

(a)

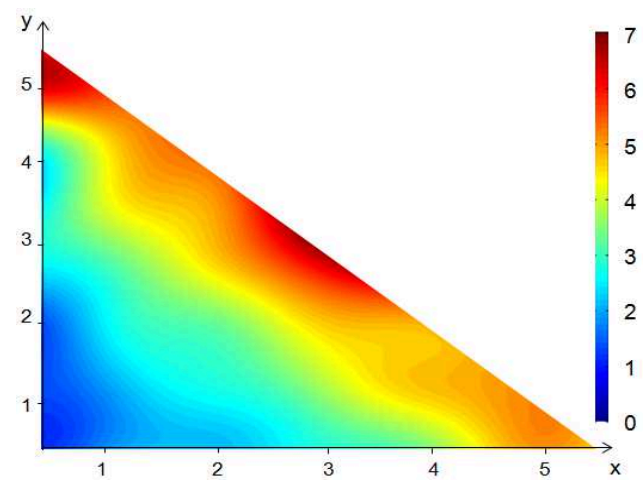

(b)

Fig. 9 Contours of the stress concentration factor $\mathrm{k}_{\mathrm{t}}$ : (a) $2 \mathrm{a}=0.3 \mathrm{~mm}$ (b) $2 \mathrm{a}=1 \mathrm{~mm}$

As presented in Fig. 9, the presence of residual stresses in the weld causes a change in the location and intensity of the stresses. Results given by FEM shows that tensile residual stress shifts the dangerous zone from the weld root zone to the extremity of the weld (on the surface). 
According to results given by numerical simulations, we can conclude that:

$$
k_{t_{\text {res }}}^{\max }=k_{t}^{\max }+2.5
$$

where $k_{t_{\text {res }}}^{\max }$ is the maximal stress concentration factor for the structure with residual stress and $k_{t}^{\max }$ is the maximal stress concentration factor for the structure without residual stress.

\section{Effect of a defect position on the residual stresses.}

It seems interesting to see the stress distribution for two locations of the porosity defect.

A defect was introduced in the weld root zone to observe its impact on stress distribution in a welding structure. As shown in Fig. 10, residual stress shift the dangerous zone from the weld root zone to the weld toe zone and the stress intensity has greatly decreased. The peak stresses decrease from 684.4 $\mathrm{MPa}\left(k_{t} \approx 3\right)$ to $397.3 \mathrm{MPa}\left(k_{t} \approx 1\right)$.

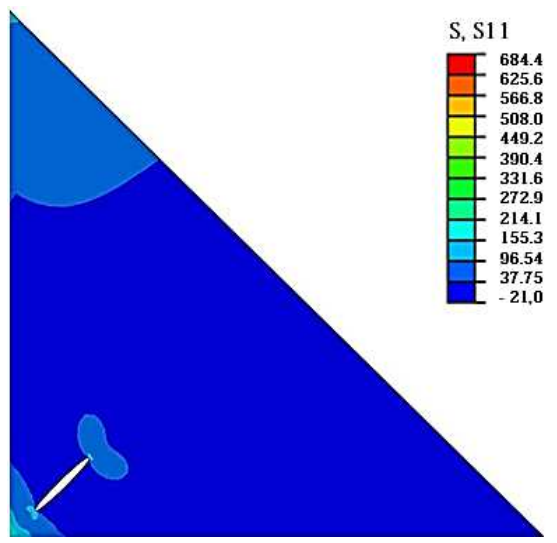

(a)

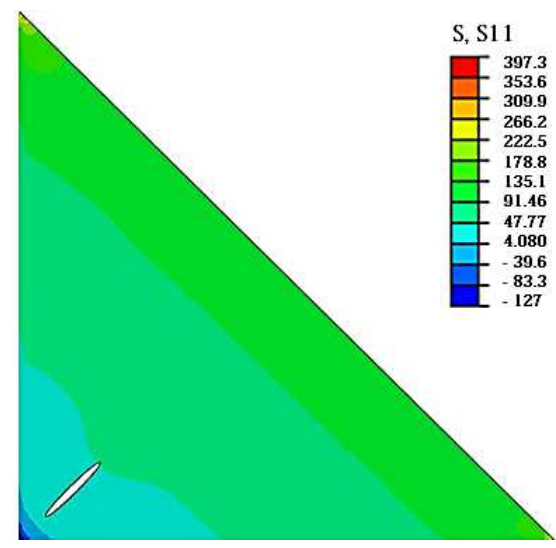

(b)

Fig. 10 The stress contour: (a), before introducing residual stress (b), after introducing residual stress

Now, the defect is located in weld toe zone, the results given by FEM is presented in Fig. 11. We concluded the same thing for the shifting of the dangerous zone but in this case the stress intensity has greatly increased. The peak stresses increase from $257.95 \mathrm{MPa}\left(k_{t} \approx 1\right)$ to $1328 \mathrm{MPa}\left(k_{t} \approx 4\right)$.

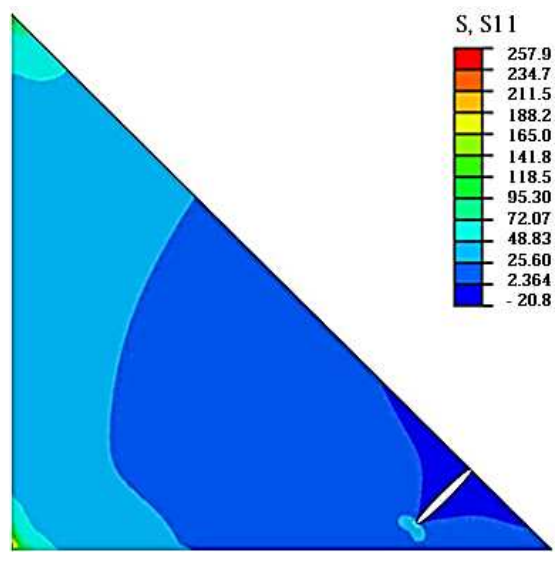

(a)

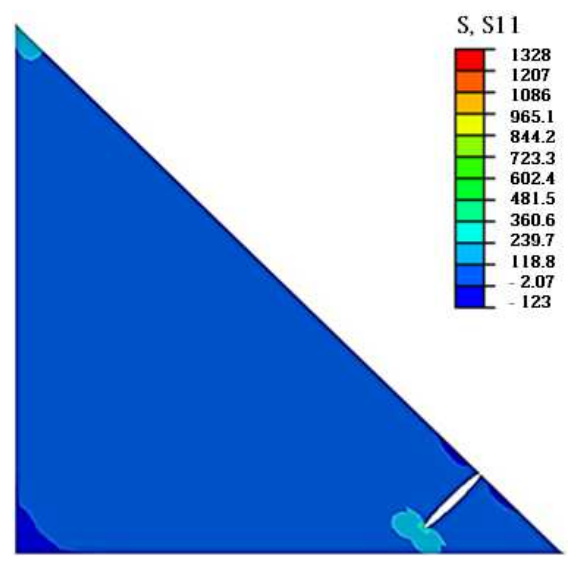

(b)

Fig. 11 The stress contour: (a), before introducing residual stress (b), after introducing residual stress

Before introducing the residual stresses on the FEM, the defect located in the weld root zone $\left(k_{t} \approx 3\right)$ is more dangerous than defect located in the weld toe zone $\left(k_{t} \approx 1\right)$. After introducing the residual stresses, the defect located in the weld toe zone $\left(k_{t} \approx 4\right)$ becomes more dangerous than defect located in the weld root zone $\left(k_{t} \approx 1\right)$. We can conclude that the residual stresses $\sigma_{11}$ are tensile into the weld toe zone and compressive in the weld root zone. So, into the weld toe zone, tensile residual stresses in addition to tensile load amplify the stress concentration factor. Nevertheless, into the weld root zone, compressive residual stresses are beneficial by reducing the tensile load. 


\section{Summary}

In this study, the stress concentration characterization of a HSLA steel weld has been carried out. According to the finite element analyzing, the following conclusions can be drawn:

- Residual stresses have important effects on the performance of the T-welded structure and may cause fatigue failure earlier than non-pre-stressed components.

- Tensile residual stresses shift the dangerous zone from the weld root zone to the weld toes zones and increases the stress intensity.

- Tensile residual stresses in addition to tensile load increase too much the stress concentration factor in the weld.

- Porosity defect has a great impact on the distribution of the stress concentration on the weld.

- The most critical defect is that located on the weld toe zone.

- Compressive residual stresses are beneficial for the root defect.

\section{Acknowledgements}

The authors acknowledge the financial supports of Champagne-Ardenne region to implement this project.

\section{References}

[1] M. Manganello, Proceedings of the international conference on processing microstructure and properties of microalloyed and other modern HSLA steels, ISS-AIME, Warrendale, PA, 1992, pp. 331-343.

[2] C.H. Lee, K.H. Chang, Prediction of residual stresses in high strength carbon steel pipe weld considering solid-state phase transformation effects, Computers and structures. 89 (2011), pp. 256265.

[3] G. Bhuyan, O. Vosikovsky, Prediction of fatigue crack initiation lives for welded plate T-joints based on the local stress-strain approach, International Journal of Fatigue. 11 (1989), pp. 153-159.

[4] I. Frih, P.A. Adragna, G. Montay, Mechanical reliability-design of high-strength steel welded structure, CFM 2013.

[5] M. Jeyakumar, T. Christopher, Defect assessment of welded specimen considering weld induced residual stresses using SINTAP procedure and FEA, Trans. Nonferrous Met. Soc., China, 23 (2013), pp. 1452-1458.

[6] J. Shi, S. Booth, An investigation of effects of welding residual stresses on creep crack growth for a low alloy butt weld, Inter. J. of Pressure Vessels and Piping, 2013, pp. 67-71.

[7] Z. Barsoum, A. Lundbäck, Simplified FE welding simulation of fillet welds - 3D effects on the formation residual stresses, Engineering Failure Analysis. 16 (2009), pp. 2281-2289.

[8] Handbook on residual stress 1, Residual stress: manufacturing and materials processing / edited by Jian Lu. - 2nd edition, 2005.

[9] A. Michel, Welded mechanical pieces - Design of joints, Technical Engineer, 2006, pp. 1-15.

[10] ABAQUS user/technical manual version 6.5. Hibbit, Karlsson and Sorensen Inc., 2007.

[11] R. Bao, X. Zhang, N. A. Yahaya, Evaluating stress intensity factors due to weld residual stresses by the weight function and finite element methods, Engineering Fracture Mechanics. 77 (2010), pp. 2550-2566. 